\title{
Description of the Female of Sciopemyia servulolimai (Damasceno \& Causey) (Diptera: Psychodidae)
}

\author{
José Dilermando Andrade Filho/ ${ }^{+}$, Eunice A Bianchi Galati*, \\ Raimundo Nonato de Sousa**, Alda Lima Falcão
}

\begin{abstract}
Laboratório de Leishmanioses, Centro de Pesquisas René Rachou-Fiocruz, Av. Augusto de Lima 1715, 30190-002 Belo Horizonte, MG, Brasil *Departamento de Epidemiologia, Faculdade de Saúde Pública, Universidade de São Paulo, São Paulo, SP, Brasil **Fundação Nacional de Saúde, Coordenação Regional do Ceará, Fortaleza, CE, Brasil
\end{abstract}

The female of Sciopemyia servulolimai (Damasceno \& Causey), based on three specimens captured during an epidemiological research project in the state of Ceará, Brazil, is described and illustrated for the first time.

Key words: Sciopemyia servulolimai - Phlebotominae - sand fly - Diptera - Psychodidae - taxonomy - Brazil

A female belonging to the genus Sciopemyia Barretto, 1962 was captured during a leishmaniasis epidemiological assay carried out in the Pacoty county, north of the state of Ceará, Brazil, in 1996. This female did not fit in with characteristics of the other females clustered in that group. In 1997, two other females similar to the first and a male of Sciopemyia servulolimai (Damasceno \& Causey) were found in the Serra da Meruoca situated at same region. The coloration pattern as well as the characters of the antennae and thorax led to the association of the genders.

Although the northern region of the Ceará is not geographically close to the type locality of this species (Bom Jesus, São Domingos, state of Pará, Brazil), both areas present similar ecological characteristics as well as fauna (Ready et al. 1983, Ryan 1986, Queiroz et al. 1991, 1994).

In the Serra da Meruoca, several cutaneous cases of leishmaniasis have been reported and the predominant phlebotomine species are Nyssomyia whitmani (Antunes \& Coutinho) and Micropygomyia quinquefer (Dyar); the former being considered the potential vector (Oliveira Lima et al. 2001).

As in the above mentioned study the sand flies were dissected to observe natural infection by flagellates, the two females captured in 1997 had only the three terminal abdominal segments and the head preserved and mounted on microscope slides in Canada medium.

The three specimens were measured with a scale adapted to an Zeiss ${ }^{\circledR}$ eye-piece and calibrated according to a standard Zeiss ${ }^{\circledR}$ scale. The drawings were made with an Olympus ${ }^{\circledR}$ camera lucida. All measurements are given in micrometers and in parentheses the measures of the other two specimens, with the respective standard deviations. The terminology of the characters and the nomenclature is in accordance with Galati (1995).

This work was supported by Fundação Nacional de Saúde and Fiocruz.

${ }^{+}$Corresponding author. Fax: +55-31-3295.3566. E-mail: jandrade@cpqrr.fiocruz.br

Received 5 June 2002

Accepted 8 April 2003
Sciopemyia servulolimai

(Figs 1-8)

A small and pale sand fly, the total length of the only presently existing complete in one specimen being 2660 , having a notum slightly darker than the pleurae.

Female. Head (Fig. 1) length $370(335 \pm 21 ; \mathrm{n}=2)$, width $360(338 ; \mathrm{n}=1)$; length/ width ratio 1.03: 1.0 $(0.95: 1.0 ; \mathrm{n}=1)$. Clypeus length $130(121 \pm 11 ; \mathrm{n}=2)$; head length/ clypeus length ratio 2.85:1.0 (2.77:1.0; $n=2)$. (2.77: $1 ; n=2)$. Inter-ocular distance $148(155 ; n=1)$. Eye length $178(175 ; n=2)$ by $105(95 \pm 7 ; n=2)$ wide; length/width ratio 1.70: $1(1.84: 1 ; \mathrm{n}=2)$. Labrum-epipharynx (LE) 198 $(188 ; n=2)$. LE/head length ratio 0.54: $1(0.56: 1 ; n=2)$. Hypopharynx with atrophied teeth of difficult visualization. Palpomeres (Fig. 2) measuring 1 - 38 (34 $\pm 6 ; \mathrm{n}=2)$; 2 - $80(86 \pm 4 ; \mathrm{n}=2) ; 3$ - $135(130 \pm 14 ; \mathrm{n}=2) ; 4$ - $80(74 \pm 16$; $\mathrm{n}=2) ; 5$ - $155(183 ; \mathrm{n}=1)$. Palpal formula: $1 .(2 \cdot 4) \cdot 3.5$ or 1.2.4.3.5 and another specimen, which do not present the palpomere 5 is: 1.4.2.3. Palpomere 3 with dispersed Newstead's spines. Each antenna has one papilla on the segments AIII (Fig. 1) and AIV (Fig. 3) but none on AV (Fig. 4). It was not possible to observe the papillae in AXIII, AXIV, AXV and AXVI, because these articles were lost. Ascoids are simple and their apex does not reach the level of the papilla. External ascoids situated more distally than internal ones on AIII, AIV and AV. AIII measures 395 $(438 \pm 28 ; n=2)$, AIII/LE ratio: $1(2.33: 1 ; n=2) ; \mathrm{AIV}-205$ $(223 \pm 7 ; n=2) ; A V-205(219 \pm 13 ; n=2)$. Cibarium (Fig. 6) with four horizontal teeth, complete arch and well defined area. Pharynx without spines with few striations in at apex.

Cervix. ventrocervical sensillae absent.

Thorax. Mesonotum measures 580 from the pre-scutum to the scutellum; pleurae have 3 proepimeral setae and 11 anepisternal superior setae; presence of setae on the anterior region of katepisternun. Wing (Fig. 7) length 1940, width 570 , length/width ratio 3.40:1. Length of the vein sections: alpha (R2) 560; beta (R2+3) 150; gamma (R2+3+4) 380; delta 230. Legs without special characters. Length of femora, tibiae, and basitarsi/ tarsi II+III+IV+V ratio: foreleg 820, 1080, 1.11:1.0; midleg 760, 1260, 1.08:1.0 and hindleg 840, 1390, 1.00:1.0.

Abdomen. Cercus (Fig. 5) length $180(176 \pm 11 ; n=2)$ 


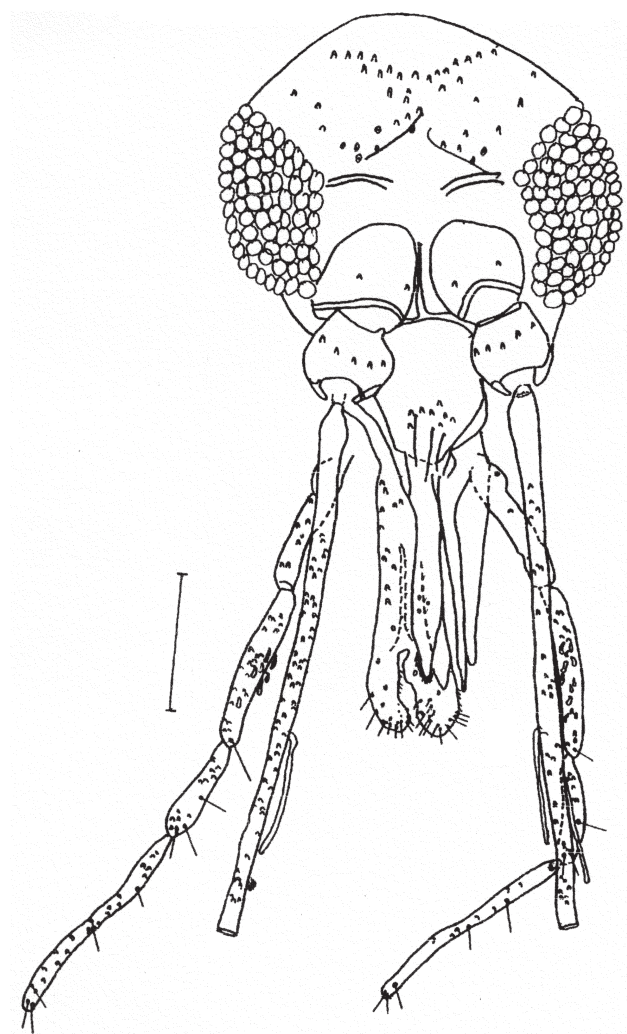

Fig 1: Sciopemyia servulolimai female, head. Bar $=100 \mu \mathrm{m}$

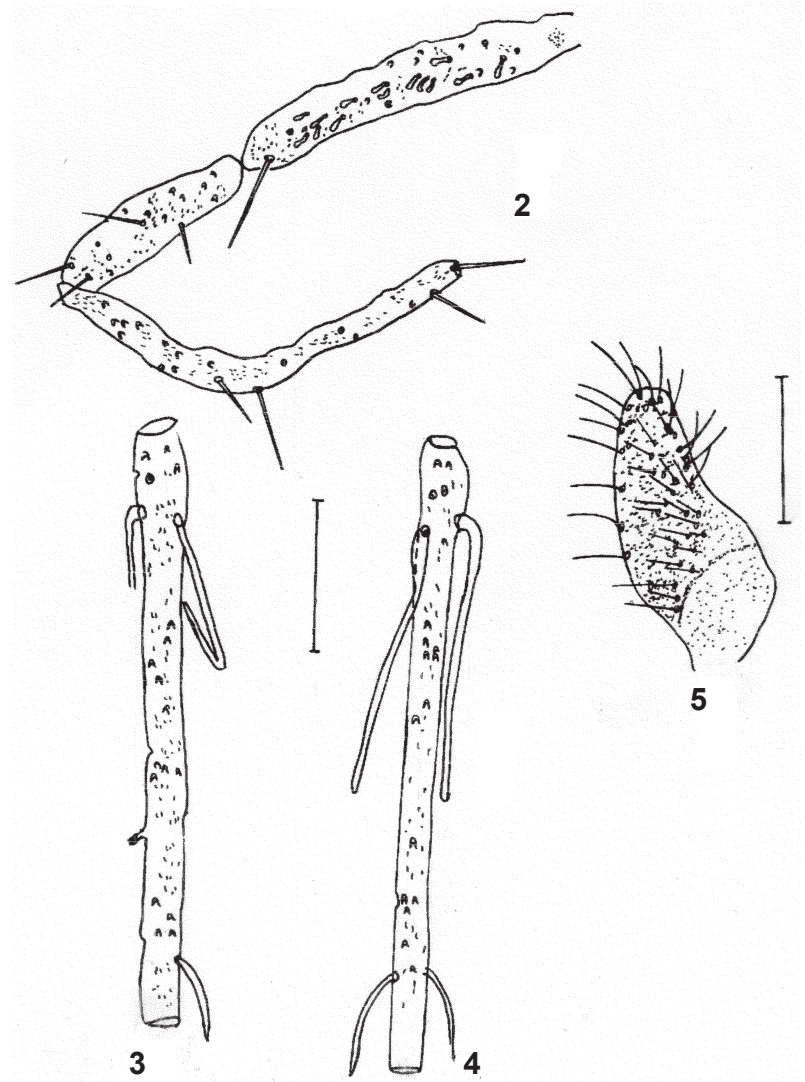

Sciopemyia servulolimai female. Fig. 2: palpomere 3, 4 and 5. Fig. 3: AIV. Fig. 4: AV. Bar $=50 \mu \mathrm{m}$. Fig. 5: cercus. Bar $=100 \mu \mathrm{m}$

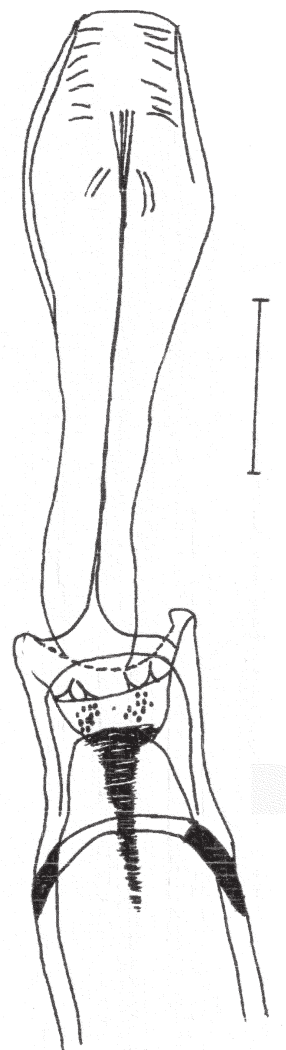

Fig. 6: Sciopemyia servulolimai female, cibarium and pharynx. Bar $=50 \mu \mathrm{m}$
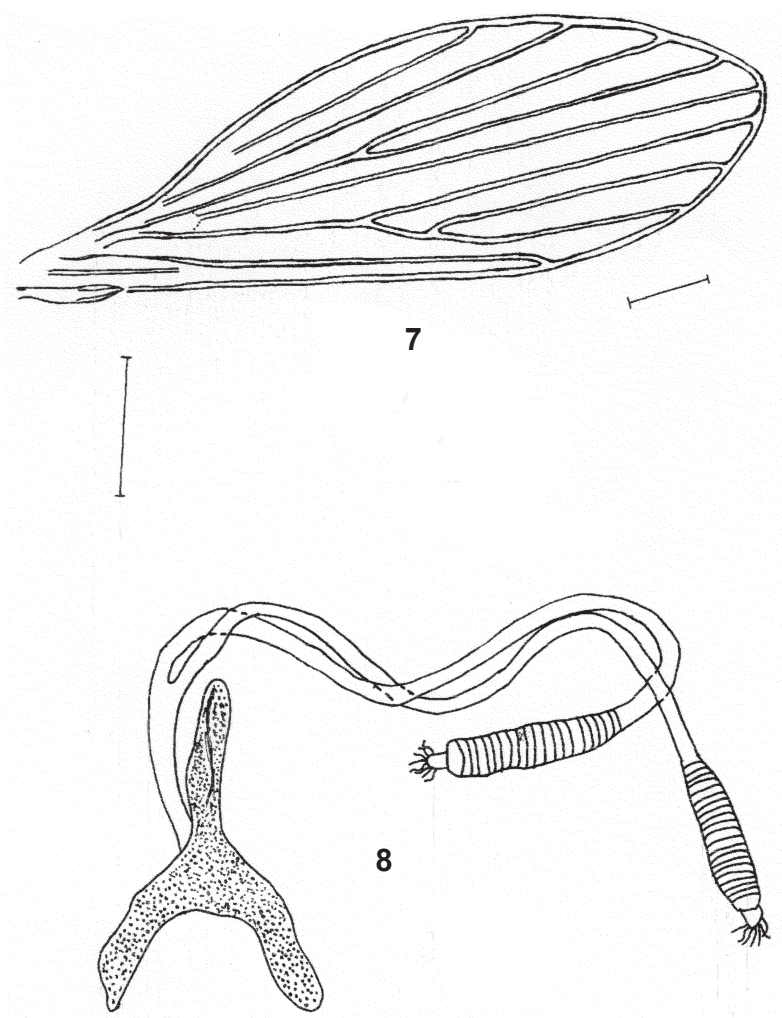

Sciopemyia servulolimai female. Fig. 7: wing. Bar $=200 \mu \mathrm{m}$. Fig. 8: spermathecae and ducts. Bar $=50 \mu \mathrm{m}$ 
without special characteristic. Spermathecae (Fig. 8) length $68(59 \pm 1 ; n=2)$ by 15 wide $(13 ; n=2)$ having $21-23$ rings, not well defined along its length and of irregular size; head very prominent. Individual duct length 235 (187 \pm $16 ; \mathrm{n}=2$ ) by 5 wide, seen to be homogeneous throughout. Ratio between the lengths of individual ducts and spermathecae 3.46:1. Common duct length 53, only visible in one specimen.

Collection data and storage of the material: two females collected, together with a male of $S$. servulolimai in 30 July 1997, in the locality of Saco dos Lopes, in Meruoca municipality, state of Ceará. The samples were collected with a CDC light trap (Eugênio col.). Other specimen was collected in 9 September 1996, on the Sitio do Meio, municipality of Pacoty, in the same state, with a CDC light trap (Nonato col.). The four samples are part of the Phlebotomine Collection of the Centro de Pesquisas René Rachou-Fiocruz, in Belo Horizonte, state of Minas Gerais. Both localities are similar, situated in a hilly region of the Baturité Massif and the Serra da Meruoca. Temperatures vary between 21 and $32^{\circ} \mathrm{C}$, with native vegetation, coffee and banana production being the main agricultural activities in the area.

\section{DISCUSSION}

The characters of the S. servulolimai female, such as the absence of ventrocervical sensillae, very long AIII, external ascoid being more apical than the inner one and presence of cerdae in the anterior region of katepisternum, permit its inclusion in the Sciopemyia genus. The absence of papilla on AV differentiates this species from Sciopemyia vattierae (Le Pont \& Desjeux) and Sciopemyia sordellii (Shannon \& Del Pont). S. servulolimai is different from Sciopemyia nematoducta (Young \& Arias) by the ratio individual duct/spermathecae, which is 3.5:1 (measured for one paratype) whereas 13.3:1 is the ratio for the latter species. S. servulolimai is different from Sciopemyia fluviatilis (Floch \& Abonnenc) because its bigger common duct; however, the junction width between individual and common ducts is narrower. It also differs from Sciopemyia preclara (Young \& Arias) in presenting a wider junction between individual duct and spermathecae and in the longer common duct.

The closest species to $S$. servulolimai is undoubtedly Sciopemyia microps (Mangabeira). Spermathecae of the allotype described by Martins et al. (1975) present a length/width ratio of $6.9: 1$, whereas that of $S$. servulolimai is 4.5:1. The horizontal teeth of the cibarium in S. microps are also more developed than those of $S$. servulolimai.

Another female resembling $S$. servulolimai is that il- lustrated by Young and Arias (1984), from material collected in Colombia, however they differ in the size of the spermathecae individual ducts that are bigger from Colombian female $(260 \mu \mathrm{m})$, being the common duct shorter $(20 \mu \mathrm{m})$ than the female of S. servulolimai. The ratio individual ducts/common duct is 13,00:1 in the female by Young and Arias (1984), and 4,43:1 in the female of $S$. servulolimai.

S. servulolimai seems to be associated with termite nests. The material of this species, deposited in the Phlebotomine Collection of the Centro de Pesquisas René Rachou, consists of seven males captured in the state of Rondônia. These were captured with a hand collector tube and a Damasceno trap, always being found in the biotype mentioned above.

\section{REFERENCES}

Galati EAB 1995. Phylogenetic sistematics of Phlebotominae (Diptera: Psychodidae) with emphasis on American groups. Bol Dir Malariol Saneam Amb 35 (Supl. 1): 133-142.

Martins AV, Falcão AL, Silva JE 1975. Estudo sobre os flebótomos do estado de Minas Gerais. X - Descrição das fêmeas de Lutzomyia microps (Mangabeira, 1942) e Lutzomyia firmatoi (Barretto, Martins \& Pelegrino, 1965) (Diptera, Psychodidae, Phlebotominae). Rev Brasil Biol 35: 259-263.

Oliveira Lima JW, Linhares FE, Rebelo IF 2001. Espécies de flebotomíneos presentes num foco de leishmaniose tegumentar na Serra da Meruoca, região norte do Ceará. Rev Soc Brasil Med Trop 34 (Suppl. 1): 80.

Queiroz RG, Vasconcelos AW, Vasconcelos IAB, Sousa RN, Pessoa FAC, Alencar JE, David JR 1991. Phlebotomine sandfly (Diptera: Psychodidae) fauna survey in an American cutaneous leishmanisis (ACL) focus in Baturité, Ceará State, Northeast Brazil. Parassitologia 33 (Suppl. 1): 159-167.

Queiroz RG, Vasconcelos IAB, Vasconcelos AW, Pessoa FAC, Sousa RN, Alencar JE, David JR 1994. Cutaneous leishmaniasis in Ceará State in Northeastern Brazil: incrimination of Lutzomyia whitmani (Diptera: Psychodidae) as a vector of Leishmania braziliensis in Baturite municipality. Am J Trop Med Hyg 50: 693-698.

Ready PD, Ribeiro AL, Lainson R, Alencar JE, Shaw JJ 1983. Presence of Psychodopygus wellcomei (Diptera: Psychodidae), a proven vector of Leishmania braziliensis braziliensis, in Ceará State. Mem Inst Oswaldo Cruz 78: 235236.

Ryan L 1986. Flebótomos do Estado do Pará, Brasil. Diptera: Psychodidae: Phlebotominae), Instituto Evandro Chagas, Ministério da Saúde, Belém, 154 pp.

Young DG, Arias JR 1984. The microps group of Lutzomyia França with descriptions of two new species from South America (Diptera: Psychodidae: Phlebotominae). Mem Inst Oswaldo Cruz 79: 425-431. 